\title{
Pampas argentinos: a percepção da monotonia
}

\author{
Raquel Alves Mota, Pós-Lit UFMG
}

Resumo: No percurso da caravana do Dr. Real pelos pampas argentinos, em Las Nubes (2000), o médico narrador busca retratar o espaço em que deambula. A fugidia realidade que acompanha as personagens enfatiza a discussão promovida por Saer, nos seus escritos teóricos, a respeito, da possibilidade de apreensão da realidade ou da delimitação dos lugares do real e da ficção.

Palavras-chave: percepção; monotonia; realidade.

"Hay una hora de la tarde en que la llanura está por decir algo; nunca lo dice o tal vez lo dice infinitamente y no lo entendemos, o lo entendemos pero es intraducible como una música..."

Borges. El fin. In: Ficciones. p. 79.

Um dos temas recorrentes da escrita de Saer é a questão do espaço narrativo ${ }^{1}$. Desde as discussões teóricas, nos livros ensaísticos, o escritor se esmera em conflitar, não apenas este lugar, mas a própria possibilidade de representação. No emblemático "El concepto de ficción" 2, Saer discute a apreensão do real pela narrativa, buscando, primeiramente, redefinir os lugares do ficcional e do real. É no emaranhado entre essas posições que surge o problema em equacionar os seus limites. No mencionado ensaio, Saer começa discutindo a biografia de Joyce ou a possibilidade de conhecer o célebre escritor por meio da escrita biográfica. A complexidade se mostra na dificuldade do biógrafo em desvincular-se da subjetividade do biografado. Segundo Saer, a aura de Joyce contamina as perspectivas escriturais do texto; assim, o biógrafo toma partido, afastando-se da aclamada objetividade deste gênero narrativo. É exatamente essa objetividade que é questionada por Saer, e nomeada de "supuesto retórico". Com essa introdução, o crítico deflagra uma das variantes do problema: como se pode defender uma narrativa que prioriza apenas a objetividade. Seguidamente, ele se foca no outro polo: a ficção seria a antípoda da verdade? No encalço de respostas, Saer promulga que o incoativo dessa relação é a questão da subjetividade. A relação do sujeito com o objeto norteará os graus de ficcionalidade de um texto.

No mencionado ensaio, a tese central se aclara no início do seu terceiro parágrafo: "El rechazo escrupuloso de todo elemento fictício no es un criterio de verdad". ${ }^{3}$ Primeiramente, Saer perscruta a tendência do gênero biográfico em se fiar de uma total objetividade, denunciando os desvios dessa conduta, na pretensão de uma narrativa factual. A investida sobre o gênero é somente uma estratégia para a comprovação da presença de elementos não objetivos dentro deste tipo de relato. A biografia trabalha na perspectiva da objetividade, como uma maneira de desvincular-se do fictício ou artificial, no intuito de se manter exclusivamente no fato concreto: Saer percebe o veio fictício nesta empresa. Da objetividade para a verdade tem-se que este último conceito é para Saer uma questão conflituosa, já que sua abrangência não pode ser cerceada. Assim, o 
que parece lhe interessar nem é tanto a verdade em si, mas rechaçar a ideia de que a biografia, e mesmo a autobiografia, tenham a verdade como escopo unívoco.

A biografia e a autobiografia são desestruturadas, na teoria saeriana, como sendo vertentes de um puro objetivismo. Walter Benjamin na tese seis de "Sobre o conceito da história" defende, num quase mesmo gesto, que o discurso histórico não representa o passado "como ele de fato foi". ${ }^{4}$ A partir disso, o filósofo advoga um rearticular da história como uma arma contra o nepotismo dos vencedores. A possibilidade dessa escritura a contrapelo denuncia a não equivalência entre o fato e os registros históricos. Walter Benjamin reclama um contra discurso que desperte a voz daqueles que foram silenciados, posteriormente ao argumento da disparidade entre discurso e fato. Nesta posição, percebe-se que o filósofo sublinha o papel dos enunciadores na conformação dos discursos. Saer identifica a função das vozes enunciativas por meio da presença da subjetividade nos textos ditos não ficcionais. Para o escritor é a subjetividade quem norteia os limites da biografia e da autobiografia, bem como de todos os textos que se nomeiam como "não-ficção", o que impede uma relação direta com a objetividade. Além deste obstáculo para a apreensão do real (a presença da subjetividade) ou a interpretação do escritor, Saer nomeia mais dois: a autenticidade das fontes e "las turbulencias de sentido propios a toda construcción verbal". ${ }^{5}$ A contradição direta entre ficção e verdade é desestruturada, em benefício dos deslocamentos e aproximações entre ambos.

No outro polo da questão Saer questiona: é possível emancipar a ficção de seus laços com a verdade, ou formulando de outra maneira, a ficção seria "uma reivindicación de lo falso". " Seria esse o objetivo da ficção, do contrário, quais seriam os seus elementos constitutivos? O conceito de ficção de Saer nasce da investida em visualizar esses componentes definidores. A ficção se mostra como um exemplo do convívio entre o objetivo e os elementos ficcionais, provindos da imaginação. $\mathrm{O}$ texto ficcional apresenta um tratamento próprio para com a verdade: seu escopo não é meramente iludir, mas, segundo Saer, demonstrar os aspectos complexos da realidade. É um salto ao inverificável ou ao que poderia ser realidade, ao "como se" ${ }^{7}$ de Iser. Para Saer, o grande paradoxo da ficção está no ato de recorrer ao falso para aumentar a credibilidade do texto, mas não com o intuito de ser tomado como verdade. A ficção apresenta-se como verdade ao mesmo tempo em que se afirma como ficção. ${ }^{8} \mathrm{O}$ falso e o verdadeiro se apresentam no ensaio como "conceptos problemáticos que encarnan la principal razón de ser de la fícción". ${ }^{9}$ A própria ficção faz desse conflito um elemento do próprio texto. É a partir disso, que Saer chega ao seu conceito: a ficção como uma "antropologia especulativa", um relato em que a subjetividade norteia os valores do mundo objetivo. Percorrer esse desenvolvimento do conceito de ficção de Saer se mostra como pressuposto para o entendimento da obra ficcional do escritor.

No presente ensaio a questão central é o tratamento da natureza, ou do espaço narrativo, no romance Las nubes (2000). Dentre outros vários, esse romance é escolhido pelo fato de focar o relato em um ambiente mais natural: os pampas argentinos. Las nubes é um dos romances históricos de Saer, no qual os acontecimentos se voltam para o séc. XIX. Antes desse recuo, a história é marcada pela discussão entre ficção e realidade, por meio de um proêmio que apresenta a história de segundo nível, ou o relato propriamente dito. Esse proêmio inicia com uma narrativa em terceira pessoa, o foco se centra sobre Pichón ${ }^{10}$, que se encontra de regresso à Paris, depois de uma temporada em sua cidade natal. Pichón conversa ao telefone com seu amigo Tomatis que deixara no outro hemisfério. Tomatis lhe promete visitar e antes disso lhe conta que um amigo comum de ambos - o Marcelo Soldi - pretende enviar um pacote para Pichón. O conteúdo chega algum tempo depois: um disquete e uma carta. Soldi antecipa, na carta, 
que o texto que digitou foi lhe entregue por uma senhora de noventa anos e que Tomatis afirma se tratar de um texto ficcional e não de um documento autêntico. Marcelo Soldi afirma, ainda, que em acordo com o conteúdo narrado o autor desconhecido não acharia inadequado que se lhe dessem o nome de Las nubes. No momento de leitura do conteúdo do disquete, a história se abre para os leitores.

A história, de segundo nível, começa em primeira pessoa. O Dr. Real narra, depois de trinta anos, os sucessos e percalços de uma viagem que fez em 1804 atravessando o deserto argentino por cem léguas, com a missão de levar alguns doentes até a casa de saúde "Las tres Acacias". Essa casa foi fundada em 1802, pelo Dr. Weiss, ao norte de Buenos Aires, não distante do rio, "con vagas reminiscencias de la Academia y del jardín de Epicuro". ${ }^{11}$ O Dr. Real conheceu o mestre holandês, Dr. Weiss, em Paris: ambos têm como função primordial não o cuidado do corpo, mas o tratamento da alma. O narrador vê na instalação dessa casa de saúde uma possibilidade de retorno à sua cidade natal. É na intensa relação entre as tentativas de reminiscências do médico e a projeção do espaço que se constrói o conflito central da narrativa. O Dr. Real afirma que o objeto de suas memórias é essa viagem "de un mes largo por la llanura". ${ }^{12} \mathrm{O}$ costume era que as famílias conduzissem os enfermos, que apresentavam diferentes inclinações de loucura, até à Casa de Salud. A viagem ocorreu devido a quatro pedidos simultâneos de internação, de regiões diferentes: a função do Dr. Real era buscá-los - todos em uma mesma cidade, que distanciava a metade do caminho de onde provinham - conduzindoos até Las tres acacias.

$\mathrm{O}$ nome dado à personagem que narra essa história de segundo nível - Dr. Real - vem conflitar com a performance das outras personagens. O Dr. Real é quem conduz a caravana de "loucos", ao mesmo tempo em que narra suas memórias no intuito de apreender o real: afirma repetidas vezes que o relato é verdadeiro. Além disso, e o que é mais relevante aqui, quando intenta descrever a natureza que envolve os viajantes, percebe-se uma agonística vontade de esgotar os limites desse espaço. ${ }^{13}$ A natureza se apresenta quase como uma personagem do relato, dada a intensidade de sua manifestação e da força das intempéries que influi sobre as personagens. A caravana do Dr. Real foi planejada para reunir quatro enfermos, um guia - o índio cristianizado Osuna -, e dois soldados. Assim, o comboio seria formado por cinco diligências, uma para cada enfermo e outra para o médico, com um prazo de percurso em torno de quinze dias. Esses cálculos foram suplantados, já que o comboio ultrapassou esses números: as diligências somaram um total de seis e mais dois carros - um armazém e outro para as mulheres que acompanhavam os soldados. O número de pessoas totalizou trinta e seis (foi recebido mais um enfermo - alguns enfermos levavam pessoas para acompanhá-los -, o proprietário do armazém, o índio Sirirí, ademais de um número maior de soldados dezesseis -, três rameiras que os acompanhavam e o sargento Lucero) e o tempo gasto foi de mais ou menos três vezes o prazo inicialmente estipulado. O conflito que acompanhará a caravana se manifestará devido à originalidade dos integrantes do grupo, ademais da resistência da natureza em deixá-los seguir o seu destino.

A viagem da Casa de Salud até a cidade, para o encontro com os enfermos, foi percorrida pelo médico, Osuna e dois soldados. Esse primeiro contato com a natureza dos pampas, já desvenda a exuberância da paisagem que os acompanha nos dois sentidos da viagem. A relação entre a natureza e a percepção desse espaço pelo sujeito - os mecanismos de sentido, aí, despendidos - conduzem o narrador a lançar dúvida quanto ao "real": 
[...] Apenas despuntaba el alba, el aire de un rosa azulado parecía inmovilizarnos en el interior de una semipenumbra glacial, sensación que contribuía a acrecentar la monotonía adormecedora del paisaje, pero el sol ya alto lo volvía cristalino, y todo era preciso, brillante y un poco irreal hasta el horizonte que, por mucho que galopáramos, parecía siempre el mismo, fijo en el mismo lugar, ese horizonte que tantos consideran como el paradigma de lo exterior, y no es más que una ilusión cambiante de nuestros sentidos. ${ }^{14}$

A relutância da natureza em transmutar-se, no progresso do trajeto, lança dúvidas quanto à percepção de sua realidade. Esse dilema atravessa toda a narrativa, a monotonia serve como elemento que deturpa a paisagem, fazendo com que o narrador suspeite, em muitos momentos, que se encontre efetivamente se movimentando. Assim, o encontro com a natureza parece algo irreal, ou melhor, não se concretiza plenamente.

No escopo de deslindar essa atitude de Saer em relação ao espaço narrado traz-se, aqui, a discussão de Merleau-Ponty sobre a eficácia dos sentidos do homem ou sobre a capacidade do sujeito em perceber o movimento das coisas. O intuito é dinamizar o horizonte filosófico presente no romance ou como Saer lança mão dessa discussão na performance de sua personagem-narradora, no ato de inventariar o espaço que lhe cerca.

(...) se já é difícil dizer que minha percepção, tal como a vivo, vai às próprias coisas, é impossível outorgar à percepção dos outros o acesso ao mundo; e, à guisa de revide, também eles me recusam o acesso que lhes nego. ${ }^{15}$

Aqui, Merleau-Ponty referenda, de certa maneira, a posição do Dr. Real, no descrédito direcionado aos sentidos. Neste momento de sua obra $O$ visível e o invisível (1992) o filósofo discute "a fé perceptiva e sua obscuridade": como a percepção pode se fiar de uma crença no pré-constituído. O filósofo exige, em sua argumentação, um "exame radical da pertencença ao mundo", como sinal de recuperação do momento de experiência. É nesse resgate que se intenta suprir as faltas de uma crença na préconstituição das coisas, bem como na filosofia reflexionante. Esta última se movimenta não mais na convicção de que se pode chegar às próprias coisas, como a primeira, mas de que o encontro se dá por meio da substituição da "confusão do mundo por um conjunto de consciências paralelas". O objetivo de Merleau-Ponty é se deslocar destes dois eixos filosóficos ${ }^{16}$, com o escopo de abarcar uma situação total, no movimento entre uma subjetividade e uma objetividade.

Retornando ao romance de Saer, o Dr. Real chega à casa da família de um dos enfermos e ali se hospeda. Esperando a chegada dos outros enfermos, o primeiro passo do médico, se manifesta na vontade de restaurar as lembranças que tinha de sua terra. $\mathrm{O}$ primeiro conflito está na dessintonia entre as recordações dos anos vividos nesta cidade e a paisagem, que se lhe apresenta:

[...] En esa ciudad supe por primera vez, por haber vuelto a ella después de muchos años, que la parte de mundo que perdura en los lugares y en las cosas que hemos desertado no nos pertenece, y que lo que llamamos de un modo abusivo el pasado, no es más que el presente colorido pero inmaterial de nuestros recuerdos. ${ }^{17}$

O médico percebe esse destoar, no jogo entre rememoração e percepção, conflito que se estenderá em outros vieses, como no movimento entre percepção e realidade. Assim, o 
romance discute os dois polos que Merleau-Ponty execrou, anteriormente, a subjetividade e a objetividade absoluta. A relação entre o sujeito e o espaço narrativo compreende grande parte da trama, mas, no encontro, entre esses dois vetores, por diversas vezes, a narrativa esbarra no inenarrável ou na incapacidade da personagem em atravessar esse imutável espaço.

A falsa impressão de imobilidade se apresenta como resultado da imutabilidade da natureza. Neste intrincado a monotonia surge com seus ingredientes: tristeza e solidão. É como se a regularidade do espaço pudesse congelar o tempo, de maneira que já não se observa o movimento. A visão do narrador estagna em determinado ponto e é neste instante que surgem dúvidas quanto ao percebido. O recorte não consegue se harmonizar com a mecânica do real, já que se percebe uma disjunção entre o percebido e o movimento próprio das coisas. A imutabilidade da vegetação e de todo o espaço provoca uma crise na facticidade do percebido. Há uma descrença nos sentidos devido à manifestação de um horizonte sempre inalcançável, eclipsado pela distância. É nesse emaranhado entre realidade - esta talvez como uma crença na pré-ordenação das coisas e esse inalcançável horizonte que o dilema se estrutura. Além disso, as desproporções entre as experiências passadas e a visão do percebido acentuam-se quando do encontro com essa monotonia. A fé perceptiva ou a crença na pré-ordenação do mundo avaliza o recorte ou as lembranças do narrador. O encontro dessas reminiscências com o espaço físico faz com que se duvide da veracidade do entorno. Percebem-se dois dilemas: o primeiro quando a monotonia se confronta com a dinâmica do real e o outro quando as reminiscências não conseguem se equiparar com essa realidade percebida. A própria história narrada pelo médico sofre uma ação de dissintonia para com o real, quando de sua recepção pelos amigos de Pichón: Tomatis e Marcelo Soldi. No proêmio inicial estas duas personagens discutiram o grau de realismo do texto recebido. Esse dilema se consolida, também, devido ao fato do texto do Dr. Real ser balizado por sua memória, já que se trata de reminiscências registradas pelo médico trinta anos após o "ocorrido".

Longo foi o período, em que o Dr. Real aguardou o momento em que poderiam deixar a cidade. As chuvas chegaram e a inundação impediu que a viagem se concretizasse. Os dias passados na região insólita foram se tornando regulares e a monotonia fazia com que o médico se impacientasse com a estagnação. A intempérie proporcionava um agravamento dessa imobilidade, no momento em que a dificuldade em se distinguir o espaço, fazia com que tudo tornasse uma e mesma coisa. Esse vício do olhar se apresenta como cara aos romances de Saer, a relação entre o observador e o observado, as deformações provindas do distanciamento e aproximação fazem com que ocorram mudanças no aspecto do objeto observado.

El que no ha visto como yo en un anochecer lluvioso de invierno una de esas ciudades perdidas de la llanura, cuando las primeras luces vacilantes comienzan a encenderse, y todo lo visible se iguala enterrado bajo la doble capa de la noche y de la intemperie, quizás cree haberla experimentado alguna vez, pero no conoce de verdad la tristeza. Acorralados por la inundación como estábamos, también la prisión del mundo, reforzada por ese cerco de agua, férrea, se duplicada. ${ }^{18}$

A grande quantidade de água que tinha caído nos primeiros dias foi substituída por um chuviscar constante, e após alguns dias um espetáculo se desenhava: a água flutuava pelo caminho na medida em que se evaporava. $\mathrm{O}$ vapor eclipsava o espaço, de forma que o narrador adjetivava essa presença de uma "água onipresente": vinda do céu, flutuando no 
ar e devastando casas por meio da cheia do rio. Passado o inverno, depois de quase dois meses, a caravana começa a mover-se rumo a seu destino. O sol propiciava o início do percurso. As "vicissitudes" e "anomalias" se manifestaram desde a partida: tendo como destino o sul, eles tiveram que rumar-se ao norte para depois retornar pelo lado oeste, devido à impossibilidade de cruzar o rio que transbordava na direção sul. Em decorrência do grande volume de chuvas, as estradas (ou os traçados pelo campo) se encontraram em péssimas condições, o que retardava a marcha.

No progresso do caminho eles rumaram-se ao deserto chegando "al centro mismo de la soledad": ${ }^{19}$ a geografia do deserto não se modificava. Fazendo uma paródia com o falso movimento de Zenon, o narrador relata que o espaço também se mantinha em repouso: “(...) el desierto es en cada una de sus partes siempre idéntico a sí mismo”. ${ }^{20} \mathrm{~A}$ monotonia retorna na passagem pelo deserto, essa planície que se estendia ao infinito, produz ilusões no espectador. $\mathrm{O}$ deserto $^{21}$ é assemelhado à visão do mar, devido à imensidão uniforme de seu espetáculo. Além da tristeza trazida inicialmente pela chuva, que retardou a caravana por dois meses, a monotonia do deserto desenhava, novamente, a solidão: “(...) nadie más que yo en el mundo sabe lo que es la soledad, lo que es el silencio". ${ }^{22}$ No percurso pelo deserto a temperatura alcançava sua máxima intensidade, fazendo dessa paisagem regular um imenso forno. A dificuldade em prosseguir a marcha, devido ao calor estonteante modificava o convívio entre os viajantes. O Dr. Real relata que eles criaram um mundo à parte, com suas próprias normas de vida. Foram dias nomeados como "irreales", em que os limites, entre loucura e razão, foram conduzidos pela vontade de sobreviver.

No inicio do relato o Dr. Real afirma que os enfermos estavam instalados em um mundo próprio "enteramente creado por su imaginación delirante, y a menudo incomprensible para los demás, parecían al abrigo de las contingencias naturales que deben soportar los que gozan de, como se dice, su entero discernimiento". ${ }^{23}$ Essa realidade própria dos "loucos" fazia com que eles adquirissem uma capa protetora contra as intempéries que lhes acompanharam no caminho. É como se o mundo da imaginação em que viviam fosse mais propício para as mudanças. Um mundo imaginativo ou mais ficcional que a todo o momento esbarrava com a realidade do narrador. O romance é o próprio encontro entre os dois mundos: realidade e imaginação. O mundo fictício dos loucos se apresenta mais propício ao diferente: a imaginação encontra livre circulação pelas intempéries. A tentativa do médico em inventariar a natureza sofre um golpe quando as vicissitudes da natureza tomam as rédeas do movimento do espaço. A busca por delinear o real e a manifestação de seus desvios - na performance dos loucos - se unem em uma narrativa tão exótica, que a todo o momento o narrador necessita reafirmar que se trata do real. O último golpe sobre a realidade apresenta-se na entrada efetiva do médico no mundo imaginário dos loucos.

Como um antígeno contra a loucura que os avizinhava, Osuna anuncia que se aproximava a "tormenta de Santa Rosa", o que traria a esperança de um alento ao calor exasperante. Dias depois as nuvens começaram a chegar juntamente com um fato imprevisto, que assim foi narrado pelo médico: "Les parecerá algo novelesco a mis lectores, pero durante días esperamos ansiosos el agua, y en lugar del agua, sobrevino el fuego". ${ }^{24} \mathrm{O}$ fogo os alcançou um pouco depois que eles conseguiram alcançar uma lagoa, que os serviu de refúgio. Conjuntamente aos animais, que ali também se refugiaram, o grupo assiste à propagação do fogo que os rodeia. Com água até ao pescoço, mulheres e homens sentiam a temperatura da água aumentar, como se estivessem no interior do inferno. O espetáculo é deslumbrante e narrado com detalhes, porém a veracidade do relato exige que o narrador demonstre ${ }^{25}$ como, em meio ao terror, ele pôde ter captado as 
nuances do movimento da paisagem. Esse compromisso com a veracidade deflagra a postura do narrador em delinear o real. Depois de um tempo acampado nas bordas da lagoa, os alcança a "tormenta de Santa Rosa". Essa última intempérie serve como ferramenta para restaurar o inverno cortado pelas vicissitudes da natureza, retornando a ordem natural das coisas. $O$ romance finaliza no momento em que se instaura o reingresso à normalidade, com o fim da jornada.

Saer trabalha reiteradamente em seus romances com narradores que, mesmo em primeira pessoa, narram a história posteriormente ao acontecimento. Essa postura acentua a discussão a respeito dos limites da ficção ou da possibilidade de retratar o acontecido. Em Las nubes percebe-se, além disso, uma exaltação da natureza dos pampas argentinos. A visão dirige a inspeção do espaço que entorna as personagens, e a todo o momento a percepção necessita ser reafirmada, já que a anormalidade acompanha a jornada. O próprio nome do romance traz à tona a questão dos limites: as nuvens representam o esvair repentino das certezas, nas mudanças constantes entre a chuvarada e a seca, entre a água e o fogo e, também, entre a loucura e a sanidade. No plano ficcional essa diluição das certezas abala os limites entre o espaço da ficção e o da verdade, no interior dos dois níveis do romance.

No emaranhado de posições enunciativas - desde a entrega do documento a Marcelo Soldi pela anciã e mesmo antes disso, quando da escrita da história pelo narradorpersonagem, após trinta anos do ocorrido - a linguagem se apresenta como o grande dilema do texto. A relação entre as instâncias discursivas ou a possibilidade de representação, que Saer discute em El concepto de ficción, se manifesta já no primeiro nível do romance, quando Tomatis duvida que a história seja um relato verdadeiro. Essa questão acentua-se em Las nubes, na medida em que o Dr. Real busca apreender o espaço que lhe cerca. No escopo de delimitar o percebido, o Dr. Real percebe que se instaura sempre uma brecha, que o impossibilita de chegar ao real. A evanescência do real faz com que o narrador intente sempre com mais ardor uma descrição mais minuciosa do espaço. Esses detalhes fazem com que o relato pareça falso ${ }^{26}$ e que se necessite uma reafirmação constante de sua veracidade. Percebe-se quase uma tentativa de atravessar o visível, no intuito de delinear a ontologia de sua forma.

Merleau-Ponty, na discussão de $O$ visível $e$ o invisível, se coloca na empresa de atravessar os limites do visível no objetivo de alcançar o invisível. Em busca da experiência, do invisível que subsidia o processo do sensível, tem-se: a ideia, que se mostra como o "dúplice do sensível e sua profundidade". A exploração do invisível requer tocar os meandros de encontro entre o visível e o invisível, já que não se observa uma antinomia, mas uma continuidade do sensível na proliferação mais abundante de seus constituintes no invisível. Merleau-Ponty percebe o segundo termo como uma justaposição de positividade sobre o visível. Assim, a experiência do visível é uma maneira de tocar o invisível, bem como todo tipo de exploração do sensível, como: "a literatura, a música, as paixões e a ciência de Lavoisier e Ampère" (MERLEAU-PONTY, 1992, p.144). O filósofo percebe que o fio que possibilita o encontro entre esses dois mundos é a linguagem. Ou melhor, a linguagem promove a retirada (ou a emigração) do mundo físico, para a evanescência do invisível, desse outro corpo, no interior de outro horizonte. A fala é comparada com a percepção, com o ato de reunir as duas faces entre o perceber e o ser percebido. Da mesma forma, no ato de perceber as significações se anexam à fala: as significações são, também, consideradas um conjunto condensado da multiplicidade da experiência.

A linguagem em Las nubes se apresenta com este teor ou como força mediadora do mundo sensível. Ao mesmo tempo em que representa, também, o movimento das 
"nuvens": um evanescente mecanismo que não consegue envolver completamente o mundo representado. A linguagem sofre com as desproporções entre o percebido e aquilo que quer representar. É nesse emaranhado que a discussão a respeito da ficcionalidade surge no próprio corpo do romance: por um lado, o Dr. Real busca dimensionar o real, por outro lado, observa-se que ele não consegue se separar do mundo dos loucos. O médico representa a força da razão ou do real no romance, porém esses dois vetores sucumbem em meio às vicissitudes da natureza e da performance dos loucos. Parece que Saer quer provar que o real é algo inatingível estando sempre mais para lá da representação. A plasticidade da linguagem serve como ferramenta no encalço do real, metamorfoseando-se no intuito de apreender o espaço narrativo. É nesse jogo entre realidade e representação que a linguagem legitima o movimento do jogo.

Resumen: En Las Nubes (2000), el médico narrador cuenta el viaje que hizo por la llanura, en compañía de su caravana. El doctor Real investiga el espacio en que deambula buscando dibujarlo en el relato. Pero, la realidad que sigue los personajes se huye de una descripción, lo que trae la discusión teórica de Saer, a respecto, de la posibilidad de aprehender la realidad, como, también, el reparto de los lugares del real y de la ficción.

Palabras clave: percepción; monotonía; realidad.

\section{Referências Bibliográficas}

BARTHES, Roland. O efeito de real. In: O rumor da língua. Tradução de Antônio Gonçalves. Lisboa: Edições 70, 1984. p. 131 - 136. (Coleção Signos, 44).

BENJAMIN, Walter. Sobre o conceito da história. In: Magia e técnica, arte e política: ensaios sobre literatura e história da cultura. 2. ed., trad. Sérgio Paulo Rouanet. São Paulo: Brasiliense, 1986, p. 222-232. - (Obras escolhidas; v. 1)

BORGES, Jorge Luis. El fin. In: Ficciones, Obras completas. Buenos Aires: Emecé Editores, 1974. v. 1.

GENETTE, Gérard. Discurso da narrativa. Tradução de Fernando Cabral Martins. 3. Ed.. Lisboa: Vega, 1995.

ISER, Wolfgang. Prefácio. In: O fictício e o imaginário. Rio de Janeiro: UERJ, 1996. p. 7-12.

ISER, Wolfgang. Os atos de fingir ou o que é fictício no texto ficcional. In: COSTA LIMA, Luiz. Teoria da literatura em suas fontes. $2^{\mathrm{a}}$ ed. Rio de Janeiro: Francisco Alves, 2002. v.2. p. 955-987.

MERLEAU-PONTY, Maurice. $O$ visível $e$ o invisível. 3. ed.. São Paulo: Editora Perspectiva S.A., 1992. 
PREMAT, Julio. La dicha de Saturno: escritura y melancolía en la obra de Juan José Saer. Rosario: Beatriz Viterbo, 2002.

SAER, Juan José. El concepto de ficción. In: . El concepto de ficción. Buenos Aires: Compañía Editora Espasa Calpe Argentina S. A. / Ariel, 1997.

SAER, Juan José. Las Nubes. $4^{\mathrm{a}}$ ed.. Buenos Aires: Seix Barral, 2000.

\section{Notas}

${ }^{1}$ PREMAT. La dicha de Saturno, p. 114: "Saer problematiza hasta la exasperación las posibilidades de la representación y los límites de la percepción".

${ }^{2}$ SAER. El concepto de ficción, p. 09.

${ }^{3}$ SAER. El concepto de ficción, p. 10.

${ }^{4}$ BENJAMIN. Sobre o conceito da história, p. 224.

${ }^{5}$ SAER. El concepto de ficción, p. 10.

${ }^{6}$ SAER. El concepto de ficción, p. 12.

${ }^{7}$ ISER. Os atos de fingir ou o que é ficticio no texto ficcional, p. 955.

${ }^{8}$ SAER. El concepto de ficción, p.16. Saer afirma: “(...) es justamente por haberse puesto al margen de lo verificable que Cervantes, Sterne, Flaubert o Kafka nos parecen enteramente dignos de crédito".

${ }^{9}$ SAER. El concepto de ficción, p. 15.

${ }^{10}$ Pichón é a personagem que recebe de seu amigo Marcelo Soldi o disquete com a história do percurso da caravana do Dr. Real pelos pampas argentinos. A discussão pungente desse primeiro nível do romance está no cogitar o teor ficcional ou verdadeiro do texto transcrito de um manuscrito. É por meio da leitura de Pichón que o leitor toma parte da história do Dr. Real.

${ }^{11}$ SAER. Las nubes, p.11.

${ }^{12}$ Ibídem.

${ }^{13}$ SAER. Las nubes, p. 34: "Al día siguiente al atardecer, llegamos por fin a la ciudad. Ni una nube, en el azul palidísimo del cielo, nos acompañó en nuestro último día de viaje, pero cuando íbamos llegando, hacia el oeste unos celajes finos, inmóviles contra el disco enorme y rojo del sol que se hundía en el horizonte, fueron cambiando de color, amarillos primero, anaranjados, rojos, violetas y azules hasta que, cuando alcanzamos, después de cruzar los dos brazos en que se divide el río Salado cuando va a volcarse en el Paraná, los primeros ranchos miserables de las afueras, el aire estaba negro porque todavía no había subido la luna y en los aleros o en el interior de los ranchos empezaban a brillar los primeros faroles".

${ }^{14}$ SAER. Las nubes, p. 30.

${ }^{15}$ MERLEAU-PONTY. O visível e o invisível, p. 21.

${ }^{16}$ MERLEAU-PONTY. O visível $e$ o invisível, p. 44: “(...) Não se trata de pôr a fé perceptiva no lugar da reflexão mas, ao contrário, de abarcar a situação total que comporta reenvio de uma a outra. O que se obtém não é um mundo maciço e opaco ou um universo do pensamento adequado; é uma reflexão que retorna sobre a espessura do mundo para iluminá-lo, mas que em seguida lhe devolve somente a sua própria luz".

${ }^{17}$ SAER. Las nubes, p. 70. 
${ }^{18}$ SAER. Las nubes, p. 59.

${ }^{19}$ SAER. Las nubes, p. 78.

${ }^{20}$ SAER. Las nubes, p. 21.

${ }^{21}$ SAER. Las nubes, p.79: “(...) Lo mismo que el mar, la llanura es únicamente variada en sus orillas: su interior es como el núcleo de lo indistinto. Desmesurada y vacía, cuando en ella se produce algún accidente, siempre se tiene la ilusión, o la impresión verídica quizás, de que es un mismo accidente que se repite. Cuando algo fuera de lo común acontece, tan intenso y nítido es su acontecer que, poco importa que haya sido fugaz o que perdure, siempre su evidencia excesiva nos parecerá problemática".

${ }^{22}$ Ibídem.

${ }^{23}$ SAER. Las nubes, p.17.

${ }^{24}$ SAER. Las nubes, p.99.

25 SAER. Las nubes, p. 101: "Si alguien puede pensar que la circunstancia que atravesábamos podía darme tiempo para admirar el atardecer, se equivoca, ya que fue en medio del ajetreo general, durante el cual cada uno, aparte de los enfermos, tenía algo que hacer, que esa belleza indiferente y sobrehumana del crespúsculo se fue formando, alcanzó la perfección, y naufragó en la noche".

${ }^{26}$ BARTHES. O efeito de real, p. 131. 